Evaluation of a gamified e-learning platform to improve traffic safety among elementary school pupils in Belgium

Peer-reviewed author version

RIAZ, Malik; CUENEN, Ariane; JANSSENS, Davy; BRIJS, Kris \& WETS, Geert (2019) Evaluation of a gamified e-learning platform to improve traffic safety among elementary school pupils in Belgium. In: Personal and Ubiquitous Computing, 23(5-6), p. 931-941..

DOI: $10.1007 / \mathrm{s} 00779-019-01221-4$

Handle: http://hdl.handle.net/1942/28374 


\title{
Evaluation of a gamified e-learning platform to improve traffic safety among elementary school pupils in Belgium
}

\author{
Riaz, Malik Sarmad; Cuenen, Ariane; Janssens, Davy; Brijs, Kris; Wets, Geert \\ UHasselt, Transportation Research Institute (IMOB), Agoralaan, 3590 Diepenbeek, Belgium
}

*Corresponding author email: Maliksarmad.riaz@uhasselt.be tel: 0032489651923

\begin{abstract}
Children are highly represented in statistics relating to road traffic injuries and fatalities. There are multiple risk factors that together create an increased risk for children in traffic, some of the major reasons include children's inability to efficiently and actively scan the environment and look for information relevant to the traffic environment, inconsistent behavior, and less developed hazard perception skills. Traffic safety education is one of the most important means for improving knowledge and skills required for children to behave safely in traffic. This study evaluated a newly developed and gamified e-learning platform meant to promote traffic safety among elementary school pupils in Belgium. Participants in this study were from four grades of elementary school and voluntarily took part in the training. They followed a self-study program at home for approximately 15 minutes per week over a period of five weeks in total. The platform included four modules: traffic knowledge, situation awareness, risk detection, and risk management. For each of these modules, a set of photos and videos were used as stimuli and selected from a database of camera recordings of real-life situations. Half of each module consisted of familiar situations for the pupils (i.e., own municipality), while the other half of each module consisted of unfamiliar situations for the pupils (i.e., other municipalities). A fifth module, 'the final', contained a mix of the first four modules. In total, 44 elementary school pupils (9-13 years old) completed the program. During the first round of measurement (i.e., the first four modules), pupils performed significantly better in the traffic knowledge module when compared to the other three modules. Further, in comparison to unfamiliar situations, pupils scored significantly higher in familiar situations. During the second round of measurement (i.e., the fifth module), pupils achieved higher scores in the risk detection and risk management modules when contrasted to the first measurement. The effect of gamification elements is discussed and the results also indicate the type of traffic safety issues to be emphasized in traffic safety education for children.
\end{abstract}

Keywords: E-learning; gamification; traffic; education; children; evaluation. 


\section{Introduction}

Road traffic accidents have been described as one of the leading causes of death among 0-19 year olds by the World Health Organization [1, 2] and ranks among the top four global causes of death in children between the ages of 5 and 14 years [3]. At the age when children are acting as independent road users, they participate in traffic mainly as pedestrians or cyclists. A study in the United States has shown that children aged 5-13 years who walk or cycle to school are at a greater risk of injury than those driven by car [4]. In Belgium, the homeschool commute for children has been identified as an area where almost $75 \%$ of the injuries or deaths involving children occurred from 2010 to 2012 [5]. This is mainly because almost all children and youth 5 to 18 years old are enrolled in school and this school commute becomes an important source of exposure to the traffic environment.

There are multiple risk factors that together create an increased risk for children in traffic, these risk factors are physical as well as behavioral. Physically, the perspective of children of a traffic environment is different than adults due to their smaller posture which makes it difficult for them to see oncoming traffic [6]. This physical disadvantage also makes it difficult for drivers to detect them and at close proximity they may be invisible below the height of a vehicle [7]. The ability to coordinate eyesight and hearing is also limited in children which results in missing dangerous situations thereby increasing the risk of traffic accidents [8]. Other than the physical disadvantages the major reasons of children overinvolvement in traffic accidents include behavioral factors, such as, their lack of ability to scan the environment properly for threats, inconsistency in behavior and in judgment inherent in young age groups [9], inattention [10], distraction (playing, talking, mobile phone use) in traffic situations, ability to estimate speed and distance, and less developed hazard perception skills [11-14]. Lack of maturity in behavioral and physical abilities limit the capacity of children to evaluate risk and make them more susceptible to crashes in traffic. However, these abilities improve with age and experience of traffic situations. To ensure that all children reach a certain ability level, offering education about traffic safety can be an effective strategy to keep children safe in traffic.

\subsection{Traffic Education}

Road traffic education is one of the main strategies of increasing traffic safety, and one of the 5 E's of traffic safety: Encouragement, Enforcement, Evaluation, Engineering and Education [15]. Studies conducted on crash investigation $[16,17]$ have found out that human factors contribute significantly to road accidents and outweigh environmental and vehicle factors. Applying the rules of the road, searching for potential hazards, remembering where they are, reacting quickly to emergency situations can decrease the number of accidents children are involved in as bicyclist and pedestrians [18].

Education has been recognized as a key method for reducing road traffic accidents [19-21], and is important for all road users as all the participants of the road are equally responsible for traffic safety. It is based on three main pillars [22]: 1) increasing knowledge and understanding of traffic rules and situations, 2) improving skills through training and, 3) increasing and/or reinforcing the positive attitudes toward risk-awareness, safety and safety of other users. The goal of educating participants of traffic is to increase safe movement and orientation in traffic, transfer of survival techniques in the short-term and safe and responsible behavior in the long-term. Traffic education must be adapted according to the age of the learner as you do not teach traffic safety in the same way to a six years old and to a twelve years old [22]. Accordingly, traffic education should be arranged in a way that considers the child's level of development as it helps children understand the traffic rules, and to improve their attitude towards road safety, which has been shown to be effective when started at younger ages [6].

\subsection{E-Learning and Gamification}

Traditional learning methods employed by teachers in schools are perceived as ineffective and boring by many students. Although teachers continuously try to use novel instructional approaches, it is largely agreed that there 
Riaz, M.S.; Cuenen, A.; Janssens, D.; Brijs, K.; Wets, G. are major problems around student motivation and engagement [23]. Schools also have game-like elements like badges (grades) and students can “level up” at the end of every academic year, however, this still doesn't engage students. In contrast, digital games and visual worlds have very high engagement among children [24]. The concept of gamification is not new in classrooms as mentioned above but its amalgamation in digital learning can help increase engagement and motivation. There are several definitions available on gamification. Werbach and Hunter [25] define gamification as "embedding game features into activities which are not games themselves”. Gamification focuses on reinforcements. Reinforcements encourage repetition of the behavior [26], and in the education domain reinforcements can be either extrinsic (prizes/money) or intrinsic (enjoyment/fun). As Skinner [26] has mentioned that only those behaviors are repeated which have satisfying outcomes. Gamification focuses on the repetition of the desired outcomes, so the required behavior becomes a habit.

The key element of gamification includes tasks that the learners have to perform. As the learners perform the tasks, they acquire points, awards and transition to higher levels. Which elements to be included in the training depends on the objectives of the training. Activities which are performed independently can bring individual awards (badges and points). Sailer, Hense [27] have discussed the game elements and their effect on psychological needs. Some of the gamification elements that can be applied in any e-learning platform are points, badges, and performance graphs. The need for competence is fulfilled by points and badges. The gamification elements in e-learning platforms have been identified as elements which improved engagement and performance of the learners, with points and progress bars increasing performance and increased retention with the e-learning platform [28] while digital badges increase user engagement and performance [29].

Other than the gamification elements, the literature shows that there are certain underlying dynamics and concepts (i.e. rapid feedback, progression, identification and freedom) in game design which have been shown to be effective in learning environments [30]. Feedback is a very critical element in learning. Frequent and targeted feedback can effectively enhance the learning process, and educators can use this in the program through continuous feedback in the form of self-paced exercises, visual cues and frequent questions and answers [31]. It can be given moment by moment, or at the end of the game [32]. Participants in a gamified environment are provided with achievement rewards to signal their progress, these can be scores (points), levels and progress bars. Progression mechanics embedded in the e-learning environment can signal participants' success towards victory [33]. Another dynamic in e-learning is the facilitation to learn anytime and anywhere, using network technologies as each learner has the freedom to decide when to learn each lesson [34, 35]. Identification with the character in a gamified learning environment can also play a positive role in learners experience as research has shown that players position themselves in the role of the game character and participate in the character's experience [36, 37].

\subsection{State of the art}

Traffic education to young children is often given through indoor lessons, outdoor training in protected areas and real traffic, and other creative techniques (e.g., traffic safety games). Regarding indoor lessons (e.g., in a classroom setting), traffic education has shown to be effective in increasing knowledge about traffic signs [6], in increasing situation awareness using a tabletop model of a traffic environment for identification of safe spots to cross [38] and changing the attitude and behavior [39, 40]. Training and evaluation of children hazard perception skills are generally conducted through computers using static [12] and dynamic [41] data from traffic environments for both children as pedestrians [13, 42] and bicyclists [43, 44]. For pedestrian training, It is normally given indoors using novel approaches such as, using simulator [45] and virtual reality [46] to train children skills for crossing a street safely. Outdoor training in protected areas and real traffic under supervision includes cycle skill training, as bicycling involves the use of both motor skills and scanning the environment for threats, many bicycle safety programs have been shown to be effective in increasing the skills of the learners [44, 47-49]. Most of these initiatives of indoor and outdoor training are for a day and a few for a week. Computerbased training has been implemented mainly for educating and training drivers [50-52], while for children it has been used in virtual reality or for a very limited time on one aspect of the traffic education (e.g., only risk perception). 
E-learning platforms or digital platforms for educating children have been used largely in the education domain to provide support to traditional learning as well as in other contexts such as to educate out of school children [53] and improve healthy eating habits [54], the potential of e-learning to train and educate learners has been recognized widely in several fields but not in the field of traffic safety.

With the advent of technology, gamification elements and mechanics have been incorporated with e-learning, and have been providing favourable results in terms of better academic outcomes and engagement with the digital platforms [55]. To the best of our knowledge, e-learning with gamification elements has not been used for training children on traffic safety.

\subsection{Aim}

Our study evaluates a newly developed gamified e-learning platform including gamification elements for training children on traffic safety. The platform focuses on 4 modules: (1) increasing knowledge about traffic rules (e.g., traffic signs, priority), (2) training learners on situation awareness (i.e., the perception of elements in the environment within a volume of time and space), (3) increasing hazard perception (identifying hazards in traffic situation) and, (4) hazard management (responding to the hazard in the proper way). A fifth module (i.e., the final), consists of a mix of these 4 modules. To our knowledge, this is the first platform which focusses on both knowledge and skills, makes use of context relevant footage (i.e., pictures and movies) and gamification elements for the traffic education training of children. Six research questions are formulated. For each research question, it was investigated whether there are differences in gender and school year.

- Research question 1: Is there a difference in performance among the modules of the program?

- Research question 2: Is there a difference between pupils’ scores on familiar and unfamiliar situations?

- Research question 3: Do pupils increase their scores during the second measurement (i.e., the fifth module)?

- $\quad$ Research question 4: Which questions do pupils find the most difficult?

- Research question 5: Did pupils differ in collecting badges?

- $\quad$ Research question 6: Did pupils differ in time spent answering each question?

\section{Methodology}

After looking at literature in the field of traffic education, the platform was developed in four major modules: knowledge, situation awareness, risk detection and risk management. These modules have been created from the three pillars of traffic education, these three pillars are increasing knowledge and understanding, improving skills through training and increasing and/or reinforcing the positive attitudes towards traffic safety [22] and previous literature on computer-based traffic education programs [50-52]. The knowledge module focuses on evaluating knowledge and understanding of traffic laws and regulations. The situation awareness and risk detection module focuses on increasing awareness about different traffic situations and detection of hazards in traffic, respectively. Risk management involves responding to a hazard in the given traffic situation. As children are mostly involved in accidents near intersections and crossings [12, 18], the platform focuses mainly on these situations. Footage for the platform was collected by capturing pictures and videos of traffic situations. A camera was mounted on the handlebar of the bicycle to have pictures and videos from a bicyclist perspective as shown in Figure 1. 


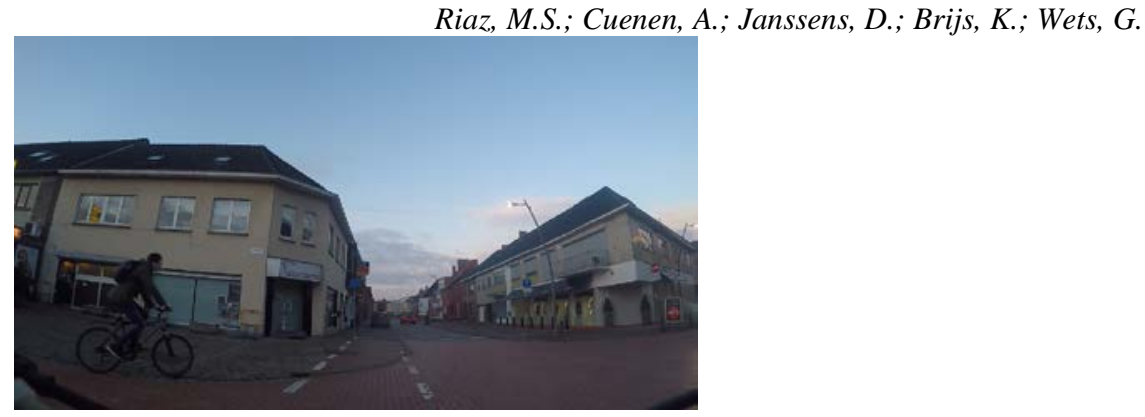

Figure 1 Example of a traffic situation in the platform.

The pictures and videos were further divided into the modules described above (i.e., knowledge, situation awareness, risk detection, risk management and the final). Each module consisted of 20 questions (10 familiar situations and 10 unfamiliar situations). Research has shown that there are discrepancies in learned skills and behaviour in unfamiliar situations for children [56]. Therefore, the first half of the training will include footage from the children's own municipality followed by the footage from other municipalities in Belgium, to see how they react to familiar and unfamiliar traffic situations. Since the child may have less risky situations in his/her own municipality, it is important to have training on various road safety elements (e.g., railway crossing), so experiencing situations not in their own municipality is vital for them, so that they are able to detect and manage risks in an unfamiliar municipality. Training children on situations in their own municipality is a priority as there is a higher chance of them encountering these situations in the short term. Extending what has been learned in familiar situations can help in reacting safely to a traffic situation in a different location. This would also help us in recognizing any transfer effects.

\subsection{Gamified e-learning platform}

Computer-based training has been used in driver education and training as road safety interventions with positive results [50-52]. The present study will be conducted on pupils (9-13-year-old) of an elementary school in Flanders (Belgium). Previous studies on driver education and training have employed multiple modules to focus on each aspect of traffic safety. The goal of this study is to increase knowledge, situation awareness, risk detection and risk management among users of the platform. For the training to be effective, it should teach the children about all the important aspects of traffic safety and let them experience these situations to some extent as doing it in real traffic can be difficult or hazardous for the children. For the current study, gamification elements like points, performance graphs, and badges are incorporated. These gamification elements have been shown to increase participants retention, and enhance the experience which will help reach the targets set out in the project. Since Learning Management Systems (LMS) can be used to deploy online courses, as customized elearning programs place high demands on design, programming skills and time, we used Moodle (Modular Object-Oriented Dynamic Learning Environment). This LMS is used for online learning and has been used by many e-learning content developers to host the learning material [29, 57, 58], as Moodle is a free and open source LMS available online (https://download.moodle.org/). It allows program developers to tailor it according to the project needs. Moodle is used either as a standalone learning environment or an addition to conventional classroom training. To access the content of the digital platform, pupils needed to log in first. They received the login information from their school director who received the information from the administrator of the platform. Once logged in, the pupils could access the content assigned to them. The digital platform provided pupils with a structured learning process, first the knowledge module was made available to the pupils in the first week followed by situation awareness in the second week, risk detection in the third week, and risk management in the fourth week. After four weeks of training, the pupils were evaluated again (second measurement) in the finale module (combination of all four modules). Within each module pupils received a question with possible answer options. After indicating an answer, pupils received a visual and audio cue if they answered the question correctly/incorrectly and detailed feedback about the correct answer. At the end of each module, pupils could 
obtain a score between 0 and 100 for each module. Dependent on the points, badges are awarded (Gold, silver, bronze and completion badge).

In addition to the gamification elements for motivation (badges), other aspects of gamification mechanics like autonomy were provided as e-learning by definition is a form of independent learning, not restricted by time and space and can benefit from individual learning style and pace [59-61]. A character named "Charlie" was used as a source of identification factor for pupils as they could relate to him as a pupil their age on a journey to and from school. A progress bar is used for each module which shows pupils how much progress they made in each module. In the second measurement (Final module), another gamification element (timer) was used, so the pupils had limited time (15 seconds) for each question in the finale module.

\subsection{Participants}

The study is conducted among pupils of an elementary school in Flanders (Belgium). Participation in this program was voluntary. 89 pupils subscribed to the program, 59 of the 89 completed at least 1 module and 44 pupils (18 male and 26 female) completed all modules. The data was collected at the end of the school year (i.e., May-June 2018). School year 3 pupils have an age of approximately 9-10 years, year 4: 10-11, year 5: 11-12, and year 6 pupils have an age of approximately 12-13 years. Hence, the minimum age of participating pupils was 9 and the maximum age was 13 .

\subsection{Study analysis}

The data was processed using SPSS (IBM Statistics 20). For each research question (except research question 3), to find the effect of gender and school year, we conducted one-way ANOVA with Gender and School year as between-subject (BS) variables, and scores (out of100) in each module as the dependent variable. For research question 3, repeated measure ANOVA is used for analyzing differences in first and second measurements with Measurement, Gender and School year as BS variables. A Bonferroni correction served to control for Type 1 errors due to multiple testing (i.e., chance capitalization). The Greenhouse-Geisser epsilon correction factor was applied to compensate for possible effects of non-sphericity in the measurements compared. Only the corrected F and probability values are reported. Alpha level of 0.05 was maintained for all statistical tests.

\section{Results}

\subsection{Demographic Analysis}

As 44 pupils (18 boys and 26 girls) completed all the modules, the data of only these pupils is analyzed. The pupils are from four school years of elementary school, which are almost evenly distributed as shown in table 1 .

Table 1 Demographic Variables

\begin{tabular}{ll}
\hline Demographic variable & $\mathbf{( N = 4 4 )}$ \\
\hline Gender & Number $(\%)$ \\
\hline Male & $18(40.90)$ \\
\hline Female & $26(59.10)$ \\
\hline Education (elementary school) & Number $(\%)$ \\
\hline 3rd year & $12(27.30)$ \\
\hline 4th year & $13(29.50)$ \\
\hline 5th year & $10(22.70)$ \\
\hline
\end{tabular}


Riaz, M.S.; Cuenen, A.; Janssens, D.; Brijs, K.; Wets, G. 6th year $9(20.50)$

\subsection{Research question 1: Is there a difference in performance among the modules of the program?}

The pupils' scores in each module were quite high, which shows that pupils already had a traffic safety supportive view. Table 2 shows the mean scores of pupils in each module.

Table 2 Mean scores and standard deviations (SD) of pupils in each module

\begin{tabular}{|l|c|c|c|}
\hline Modules & Mean Score (SD) & $\begin{array}{l}\text { Mean Score } \\
\text { Familiar Situations } \\
\text { (SD) }\end{array}$ & $\begin{array}{l}\text { Mean Score } \\
\text { Unfamiliar Situations } \\
\text { (SD) }\end{array}$ \\
\hline Knowledge & $90.23(9.587)$ & $93.41(8.053)$ & $87.05(10.018)$ \\
\hline $\begin{array}{l}\text { Situation } \\
\text { Awareness }\end{array}$ & $78.41(14.847)$ & $78.64(12.684)$ & $78.18(16.882)$ \\
\hline Risk Detection & $83.98(13.178)$ & $90.91(10.074)$ & $77.05(12.310)$ \\
\hline Risk Management & $90.11(9.884)$ & $91.82(10.842)$ & $88.41(8.611)$ \\
\hline Finale & $85.34(7.880)$ & - & - \\
\hline
\end{tabular}

There were significant differences among the modules in mean scores, $F(4,391)=15.474 p<0.001$. The scores in the knowledge module are significantly higher than both, situation awareness and risk detection modules $(\mathrm{p}<0.01)$.

Table 3a and 3b show the mean scores per gender and school year respectively in each module.

Table 3a Mean scores in each module based on gender

\begin{tabular}{|l|l|c|l|l|}
\hline Gender & Module & Mean (SD) & $\begin{array}{l}\text { Familiar situations } \\
- \text { Mean (SD) }\end{array}$ & $\begin{array}{l}\text { Unfamiliar situations - } \\
\text { Mean (SD) }\end{array}$ \\
\hline Boys & Knowledge & $90.28(10.28)$ & $94.44(7.84)$ & $86.11(10.92)$ \\
\hline & Situation awareness & $79.72(15.76)$ & $80.00(10.85)$ & $79.44(19.84)$ \\
\hline & Risk detection & $85.00(11.08)$ & $90.56(9.38)$ & $79.44(9.98)$ \\
\hline & Risk Management & $91.11(7.85)$ & $93.89(8.50)$ & $88.33(6.18)$ \\
\hline Girls & Finale & $83.89(7.58)$ & & \\
\hline & Knowledge & $90.19(9.18)$ & $92.69(8.27)$ & $87.69(9.51)$ \\
\hline & Situation awareness & $77.50(14.26)$ & $77.69(13.95)$ & $77.31(14.85)$ \\
\hline & Risk detection & $83.21(14.51)$ & $91.15(10.71)$ & $75.38(13.63)$ \\
\hline & Risk Management & $89.42(11.01)$ & $90.38(12.16)$ & $88.46(10.08)$ \\
\hline & Finale & $86.35(8.07)$ & & \\
\hline
\end{tabular}

Table 3b Mean scores in each module based on school year

\begin{tabular}{|l|l|l|l|l|}
\hline Year & Module & Mean (SD) & $\begin{array}{l}\text { Familiar situations } \\
\text { - Mean (SD) }\end{array}$ & $\begin{array}{l}\text { Unfamiliar situations - } \\
\text { Mean (SD) }\end{array}$ \\
\hline Year 3 & Knowledge & $92.92(9.08)$ & $95.83(6.69)$ & $90.00(10.44)$ \\
\hline & Situation awareness & $85.42(14.74)$ & $85.00(15.08)$ & $85.83(15.05)$ \\
\hline & Risk detection & $83.75(11.73)$ & $91.67(8.34)$ & $75.83(9.00)$ \\
\hline & Risk Management & $88.33(10.90)$ & $88.33(12.67)$ & $88.33(9.37)$ \\
\hline & Finale & $89.17(7.33)$ & & \\
\hline
\end{tabular}


Evaluation of a gamified e-learning platform to improve traffic safety among elementary school pupils in Belgium

\begin{tabular}{|c|c|c|c|c|}
\hline Year 4 & Knowledge & 92.31 (9.51) & $96.15(5.06)$ & 88.46 (11.43) \\
\hline & Situation awareness & $78.46(13.86)$ & $78.46(9.87)$ & $78.46(9.87)$ \\
\hline & Risk detection & 85.39 (15.30) & $93.08(9.47)$ & $77.69(16.41)$ \\
\hline & Risk Management & $93.47(7.45)$ & 93.85 (9.61) & $93.08(4.80)$ \\
\hline & Finale & $83.85(7.12)$ & & \\
\hline \multirow[t]{5}{*}{ Year 5} & Knowledge & $86.00(9.40)$ & $88.00(10.33)$ & $84.00(8.43)$ \\
\hline & Situation awareness & 73.50 (15.99) & $75.00(11.79)$ & $72.00(19.89)$ \\
\hline & Risk detection & $80.00(14.14)$ & $86.00(11.74)$ & $74.00(14.30)$ \\
\hline & Risk Management & $89.00(10.21)$ & $91.00(11.97)$ & $87.00(8.23)$ \\
\hline & Finale & $84.50(8.64)$ & & \\
\hline \multirow[t]{5}{*}{ Year 6} & Knowledge & $88.33(9.24)$ & $92.22(8.33)$ & $84.44(8.82)$ \\
\hline & Situation awareness & 75.00 (12.49) & $74.44(12.36)$ & $75.56(13.33)$ \\
\hline & Risk detection & 86.67 (10.29) & $92.22(10.93)$ & $81.11(6.01)$ \\
\hline & Risk Management & 88.89 (10.79) & $94.44(8.82)$ & $83.33(10.00)$ \\
\hline & Finale & $83.33(8.29)$ & & \\
\hline
\end{tabular}

There were no significant differences between the mean scores for boys $(86.23)$ and girls $(85.24),(F(1,394)=$ $0.610, p=0.435$ ), while significant differences were found among scores of the four school years, $F(3,392)=3.757$ $\mathrm{p}=0.01$. Further analyses indicated that Year 3 pupils performed significantly better than year 5 pupils $(\mathrm{p}=0.015)$.

\subsection{Research question 2: Is there a difference between pupils' scores on familiar and unfamiliar situations?}

As shown in table 2 and table 3, pupils performed significantly better in familiar situations, F $(1,350)=19.59$ $\mathrm{p}<0.001$, with a score of 88.69 in familiar situations and 82.67 in unfamiliar situations. There are no differences in gender $\mathrm{F}(1,336)=1.856$, $\mathrm{p}=0.174$ and school year $\mathrm{F}(3,172)=1.902, \mathrm{p}=0.131$.

\subsection{Research question 3: Do pupils increase their scores during the second measurement?}

The data analysis shows that pupils improved their scores when they saw the same questions again, as they had detailed feedback on each question earlier. The pupils scored $83.29 \%$ in the first attempt and improved their scores to $85.34 \%$ in the second attempt on the same questions. Table 4 shows mean scores in the four modules on pupils attempting the questions the first time and then in the finale (second measurement) module.

Table 4 Pre-Post score mean values

\begin{tabular}{|l|c|c|c|}
\hline Module & $\begin{array}{l}\text { Mean Scores - } \\
\text { First measurement }\end{array}$ & $\begin{array}{l}\text { Mean Scores - } \\
\text { Second } \\
\text { measurement }\end{array}$ & Change \\
\hline Knowledge & 82.95 & 78.67 & -4.28 \\
\hline Situation awareness & 84.90 & 78.18 & -6.72 \\
\hline Risk detection & 81.55 & 83.15 & +1.06 \\
\hline Risk management & 87.11 & 98.87 & $+11.76^{* *}$ \\
\hline
\end{tabular}


Riaz, M.S.; Cuenen, A.; Janssens, D.; Brijs, K.; Wets, G. There were no effects of Gender and School year found in the first and second measurement. There was a main effect of Measurement, $F(4,209)=6.111, p<0.0001$. As shown in Table 4, the scores in risk detection and risk management modules increased in the 'finale' module. When the same questions were presented, the change in knowledge and situation awareness is negative but not statistically significant. The boys scored $83.89 \%$ in the second measurement, while girls scored $86.34 \%$. However, this difference is not significant $(\mathrm{p}=0.311)$. Table $3 \mathrm{~b}$ shows that year 3 pupils scored the highest in the second measurement (89.17\%), but this difference is not significantly more than the other school year pupils $(\mathrm{p}=0.266)$.

\subsection{Research question 4: Which questions do pupils find the most difficult?}

We identified the five questions which pupils found the most difficult in the platform, 2 of the 5 questions with the lowest scores (more than $50 \%$ of the pupils gave a wrong answer) belong to the module of situation awareness, 2 questions were related to the risk detection module and 1 of the 5 questions was from the risk management module. In addition, four of the five questions which pupils found difficult are from unfamiliar situations (other municipalities).

There were no significant differences among genders in these questions, $F(1,218)=0.161, p=0.688$, there is also no effect of the school year in these questions $F(3,216)=0.917, \mathrm{p}=0.433$.

\subsection{Research question 5: Did pupils differ in collecting badges?}

Badges were added for pupils to gamify the platform. More than $50 \%$ of the badges won are gold badges. Among the four education modules, pupils got the most gold badges in the Knowledge module, while the lowest in situation awareness. There are no significant differences between genders in collection of badges $F(1,394)=$ $1.971, \mathrm{p}>0.05$. As shown in table $3 \mathrm{~b}$, year 3 pupils performed significantly better than year 5 pupils, hence they also collected more badges $F(3,392)=3.293 \mathrm{p}<0.05$ as can be seen in table 6 .

Table 6 Types of badges collected by pupils

\begin{tabular}{|l|l|}
\hline Badges & Number (\%) \\
\hline Gold & $221(55.8)$ \\
\hline Silver & $148(37.4)$ \\
\hline Bronze & $24(6.1)$ \\
\hline Completion badge & $3(0.8)$ \\
\hline Total & $396(100)$ \\
\hline
\end{tabular}

\subsection{Research question 6: Did pupils differ in the time spent answering each question?}

As can be seen in Table 7, pupils spent significantly more time answering knowledge and risk management questions (17 seconds), as compared to situation awareness (10 seconds) and risk detection (11 seconds), $(\mathrm{p}<0.0001)$. The least time is spent on finale questions (7 seconds) as these questions had a time limit of 15 seconds per question.

Table 7 Time spent per question in different modules

\begin{tabular}{|l|c|}
\hline Education Module & Time (seconds) \\
\hline Knowledge & 17 \\
\hline Situation Awareness & 10 \\
\hline Risk Detection & 11 \\
\hline Risk management & 17 \\
\hline
\end{tabular}




\begin{tabular}{|l|l|} 
Finale & 07 \\
\hline
\end{tabular}

As shown in Table 8, there are significant differences among time spent per gender. boys spent 12 seconds per question, while girls spent 13 seconds per question, $(\mathrm{F}(1,4397)=6.537, \mathrm{p}<0.05)$. In addition, there are significant differences among all education years for time spent on each question during the program, $\mathrm{F}(3,4395)$ $=56.471, \mathrm{p}<0.01$. The higher the school year, the less time pupils spent on answering the questions.

\section{Table 8 Time spent per question based on the school year and gender}

\begin{tabular}{|l|c|c|c|}
\hline $\begin{array}{l}\text { School } \\
\text { Year }\end{array}$ & $\begin{array}{c}\text { Time } \\
\text { (seconds) }\end{array}$ & $\begin{array}{c}\text { Boys } \\
\text { (seconds) }\end{array}$ & $\begin{array}{c}\text { Girls } \\
\text { (seconds) }\end{array}$ \\
\hline $3^{\text {rd }}$ & 15 & 14 & 17 \\
\hline $4^{\text {th }}$ & 13 & 12 & 14 \\
\hline $5^{\text {th }}$ & 11 & 10 & 12 \\
\hline $6^{\text {th }}$ & 10 & 10 & 10 \\
\hline
\end{tabular}

\section{Discussion}

89 pupils subscribed to the program. 59 pupils completed one or multiple modules, but only 44 pupils completed all modules. This drop rate could be explained as the study was conducted at the end of the academic year, and pupils being busy with other tasks or lack of time, and issues with access to the internet may have impacted the participation in this voluntary training.

During the first measurement, no difference was found among boys and girls performance, this is in line with earlier research which has shown that at a young age there are no differences of gender in crossing behaviors of children [63] and Meyer, Sagberg, \& Torquato, 2014 found that a significant gender effect was found in only one of the ten situations of risk perception of children [64]. The pupils performed significantly better in the knowledge module in the first measurement, compared to the other three modules which shows that the pupils have satisfactory knowledge about traffic laws. This could be because schools pay more attention to educating pupils on traffic knowledge as compared to developing skills required to navigate a traffic situation. Literature has shown that the transfer between knowledge and behavior in traffic is generally poor [65]. We also found that the five most difficult questions encountered by pupils in the platform were from situation awareness, risk detection and risk management further indicating that pupils have more problems with questions related to traffic safety skills and performed significantly better in the knowledge module. If the pupils have recognized the traffic sign and know what it means or they are already knowledgeable about the traffic laws (red light), it may not always result in a safer experience [66] and they may still not pay attention to the surrounding road elements and lack appropriate skills to behave safely in traffic. Therefore, schools and traffic safety practitioners should, in addition to educating children on traffic safety knowledge, also focus on developing the skills of pupils. Digital platforms like the one evaluated here, can help the pupils experience the traffic situation to some extent and in developing the skills necessary to traverse a road segment safely.

In addition, pupils scored significantly higher in familiar situations as compared to unfamiliar situations and four of the top five most difficult questions in the platform were also from unfamiliar situations. This can be attributed to pupils being familiar with the traffic scenario in their own municipality, but not able to transfer the knowledge and awareness towards other municipalities and unfamiliar situations, previous studies have also demonstrated this [56, 67]. As the criteria for using familiar and unfamiliar situation is based on children's geographical location, it is possible that although they receive situations from their own municipality but they may not have been in a specific street in their own municipality. 
Riaz, M.S.; Cuenen, A.; Janssens, D.; Brijs, K.; Wets, G. The second measurement results show pupils were able to increase their scores in the questions, probably because of the detailed feedback given in the first measurement. During the second measurement, pupils had higher scores on risk detection and risk management modules as compared to the first measurement. As mentioned above with high baseline scores in the first measurement of knowledge module, there was less room for improvement in the second measurement, while the program was successful in increasing the pupils' scores in the risk detection and management modules.

The results in our study suggest that e-learning platform with gamification elements was successful in keeping children motivated and increased their performance which was also the case in the research carried out by Klawe [68] in a six-year long project E-GEMS (Electronic Games for Education in Math and Science) demonstrated that games increased children's motivation and academic achievement in math and science education in grade 48.

Digital badges were added in the platform to motivate and reward the pupils which have been empirically shown to enhance learning [69] and help in providing a record of the skills and achievements that pupils have gained through their participation in the platform [70], In the current study, more than $50 \%$ of the badges won were gold badges which may have kept pupils engaged and motivated to perform better and keep collecting the badges, as they were shown on each pupil's profile. In terms of times spent per module per question, the most time was spent on knowledge and risk management (17 seconds) while the least time was spent on the questions in the finale module. This could be because of the timer element in the finale module (limited time) which resulted in pupils spending less time per question. Another interesting finding is that boys on average spent less time answering each question as compared to girls, this is in line with the research carried out by Klawe [68], the results showed that boys make faster progress in educational games, even though there are no significant differences in terms of performance in the subject matter, which is the case in the current study as well. The study also showed that most girls, especially aged 10 and older, are less interested in using computers in general. In addition, recent research also confirms that boys have a higher positive perception of e-learning than girls [71]. We also saw that higher the school year, hence the age of pupils, the less time they spent answering each question. This can be attributed to the reading skills of the pupils as shown by Vlachos and Papadimitriou [72] that there is a significant effect of age in reading performance of pupils with older pupils having better scores than younger ones in fluency, comprehension and the overall reading performance.

\section{Limitations and future research}

Some of the limitations of the current study need to be mentioned here. Firstly, the study was an evaluation of a prototype platform for traffic safety where pupils from a Flemish primary school participated voluntarily. Hence, the current sample size is not representative for the population and in future evaluations, more participation can further emphasize the benefits of using the digital platform. However, these results already allow us to see the potential of e-learning and gamification in improving skills and knowledge related to traffic safety of participating pupils. Second, although the footage was taken from the municipality of the pupils, the platform should be further improved to ensure more familiarity of situations so that pupils get questions about situations nearby their school since most accidents involving children occur within 500m of the school gate [73]. Hence, the platform already focuses on 'context relevant learning', i.e., selection of content relevant to the learners' situation [74], but it could be made even more contextually relevant.

In addition, the feedback was the same for all pupils, independent of their answer. Although this feedback is phrased in a way that it is relevant for all pupils, it should be better if feedback is also tailored to the individual so that specific aspects could be emphasized based on the pupil's characteristics.

These findings will be of practical interest to teaching and learning practitioners working in a range of educational contexts, who wish to increase student engagement and enhance learning using gamified e-learning platforms. Third, the current study only evaluated the program with first and second measurement without a control group. In case a control group was used, more detailed effects could be investigated. For example, when a group that followed the platform without feedback was used, the merits of feedback could be investigated. In addition, when a group that followed the platform without gamification elements was used, the merits of 
gamification could be investigated. Future research should evaluate the platform using a pre-post design in order to check whether (socio-cognitive determinants of) behavior has improved. The future studies can also include behavior observation in a naturalistic setting to see if they perform the correct behavior in real life as well after the traffic safety education [63, 75] and an eye tracker to observe phenomena like "looked but failed to see" [76], if pupils saw the risk in the traffic situation but did not respond to it. Related to this, it would also be important to investigate long-term effects of such an intervention, and to see if there is a necessity to have booster sessions, periodically, to reinforce the progress made by the intervention.

\section{Conclusions}

The study presents a gamified e-learning platform to educate elementary school children on traffic safety. The current endeavour is a first gamified digital e-learning platform in traffic safety domain that focuses on both knowledge and skills, and employs gamification elements and context-relevant footage to enhance pupils' learning and motivation to use the platform. The computer-based training was a voluntary participation program for the pupils from four school years of elementary school (age 9-13), who have been identified in the literature to be one of the most vulnerable age group in traffic.

Results showed that pupils performed significantly better in the knowledge module during the first measurement which shows that pupils already have a satisfactory level of knowledge about traffic laws and had difficulties with the skill-based situations as the five most difficult questions in the module did not include a situation from the knowledge module. Pupils also performed significantly better in familiar situations as compared to unfamiliar situations. They were able to increase their scores in the second measurement in the module of risk management, although the pupils already had high scores in each module during the first measurement. Hence, the program was still able to significantly improve the score in the module of risk management. This demonstrates the potential of digital learning in the field of traffic safety. Although this was only a pilot study, these results can guide future researchers in the domain of traffic safety among pupils.

\section{References}

1. WHO, Global Status Report on Road Safety 2015.

2. WHO, Children and road traffic injuries. . 2014.

3. $\quad$ WHO, Ten strategies for keeping children safe on the road 2015.

4. Lavoie, M., et al., Active and safe transportation of elementary-school students: Comparative analysis of the risks of injury associated with children travelling by car, walking and cycling between home and school. Vol. 34. 2014. 195-202.

5. Roynard, M., A. Schoeters, and M. Wénin, Safe to school: Analysis of road accidents involving children near primary schools and kindergardens B.R.S.I.K.C.R. Safety, Editor. 2015.

6. Trifunovic, A., et al., The importance of spatial orientation and knowledge of traffic signs for children's traffic safety. Accid Anal Prev, 2017. 102: p. 81-92.

7. Ivarsson, B.J., J.R. Crandall, and M. Okamoto, Influence of age-related stature on the frequency of body region injury and overall injury severity in child pedestrian casualties. Traffic Injury Prevention, 2006. 7(3): p. 290-298.

8. Olofsson, E., Children injured in traffic in a medical and psychosocial perspective : causes and consequences. 2014, University of Gothenburg. Sahlgrenska Academy.

9. $\quad$ Thornton, S., Taking the child's perspective seriously. Psychologist (London, England : 1988 ), 1999. 12(8): p. 393-394.

10. Benjaminsen, C. How attentive are children in traffic? 201620 January 2019]; Available from: http://sciencenordic.com/how-attentive-are-children-traffic. 
Riaz, M.S.; Cuenen, A.; Janssens, D.; Brijs, K.; Wets, G.

11. Connelly, M.L., et al., Child pedestrians' crossing gap thresholds1This research was completed by the first two authors as a graduate student research project undertaken as a part of their Master of Social Science degrees.1. Accident Analysis \& Prevention, 1998. 30(4): p. 443-453.

12. Scialfa, C., et al., The effects of driving experience on responses to a static hazard perception test. Accident Analysis \& Prevention, 2012. 45: p. 547-553.

13. Meir, A., T. Oron-Gilad, and Y. Parmet, Can child-pedestrians' hazard perception skills be enhanced? Accident Analysis \& Prevention, 2015. 83: p. 101-110.

14. Ellis, J., Bicycle safety education for children from a developmental and learning perspective. 2014, : Washington, DC: National Highway Traffic Safety Administration.

15. DOT. ConnDOT: SRTS - The 5 E's. 2019 [cited 4 Feb 2019; Available from: https://www.ct.gov/dot/cwp/view.asp?a=2094\&q=587942.

16. Thomas, P., et al., Identifying the causes of road crashes in Europe. Annals of advances in automotive medicine. Association for the Advancement of Automotive Medicine. Annual Scientific Conference, 2013. 57: p. 13-22.

17. Treat, J.R., et al., Tri-level study of the causes of traffic accidents: final report. Volume I: causal factor tabulations and assessments. 1977. 609 p.

18. Oikawa, S., et al., Traffic Accidents Involving Cyclists Identifying Causal Factors Using Questionnaire Survey, Traffic Accident Data, and Real-World Observation. Stapp Car Crash Journal, 2016. 60: p. 183198.

19. Assailly, J.P., Road safety education: What works? Patient Educ Couns, 2017. 100 Suppl 1: p. S24S29.

20. Obregón-Biosca, S.A., et al., Rating road traffic education. Transportation Research Part F: Traffic Psychology and Behaviour, 2018. 56: p. 33-45.

21. Twisk, D.A., et al., Five road safety education programmes for young adolescent pedestrians and cyclists: a multi-programme evaluation in a field setting. Accid Anal Prev, 2014. 66: p. 55-61.

22. ROSE 25 E.U., Report Inventory and compiling of a European good practice guide on road safety education targeted at young people. 2005.

23. Lee, J. and J. Hammer, Gamification in Education: What, How, Why Bother? Vol. 15. 2011. 1-5.

24. McGonigal, J., Reality is Broken: Why Games Make Us Better and How They Can Change the World. Vol. 22. 2011.

25. Werbach, K. and D. Hunter, For the Win: How Game Thinking can Revolutionize your Business. 2012.

26. Skinner, B.F., The behavior of organisms: an experimental analysis. The behavior of organisms: an experimental analysis. 1938, Oxford, England: Appleton-Century. 457-457.

27. Sailer, M., et al., How gamification motivates: An experimental study of the effects of specific game design elements on psychological need satisfaction. Computers in Human Behavior, 2017. 69: p. 371380 .

28. Krause, M. and J. Williams, A Playful Game Changer: Fostering Student Retention in Online Education with Social Gamification. 2015.

29. Facey-Shaw, L., et al. A Moodle-based Badge System for Evaluating the Motivational Levels of Introductory Programmers. in MATEL 2015 2015. Toledo, Spain.

30. Stott, A. and C. Neustaedter, Analysis of Gamification in Education. 2013.

31. Kapp, K.M., Games, Gamification, and the Quest for Learner Engagement. Training and Development 2012. 66(6): p. 64-68.

32. Gee, J.P., The Ecology of Games: Connecting Youth, Games, and Learning. 2008, The John D. and Catherine T. MacArthur Foundation Series on Digital Media and Learning: Cambridge, MA: The MIT Press. p. 21-40.

33. Robson, K., et al., Is it all a game? Understanding the principles of gamification. Business Horizons, 2015. 58(4): p. 411-420.

34. Liaw, S.-S., Investigating students' perceived satisfaction, behavioral intention, and effectiveness of elearning: A case study of the Blackboard system. Computers \& Education, 2008. 51(2): p. 864-873. 
35. Liaw, S.-S. and H.-M. Huang, Perceived satisfaction, perceived usefulness and interactive learning environments as predictors to self-regulation in e-learning environments. Computers \& Education, 2013. 60(1): p. 14-24.

36. Looy, J., C. Courtois, and M. De Vocht, Player identification in online games: Validation of a scale for measuring identification in MMORPGs. 2010. 126-134.

37. Oksanen, K., J. Looy, and F. De Grove, Avatar identification in serious games: the role of avatar identification in the learning experience of a serious game, in 63rd International Communication Association (ICA) Annual Conference. 2013: London, UK. p. 3.

38. Fyhri, A., T. Bjørnskau, and P. Ulleberg, Traffic education for children with a tabletop model. Transportation Research Part F: Traffic Psychology and Behaviour, 2004. 7(4-5): p. 197-207.

39. Hawley, C.A., R. Smith, and L. Goodwin, Road safety education for older drivers: Evaluation of a classroom-based training initiative. Transportation Research Part F: Traffic Psychology and Behaviour, 2017.

40. Ben-Bassat, T. and S. Avnieli, The effect of a road safety educational program for kindergarten children on their parents' behavior and knowledge. Accident Analysis \& Prevention, 2016. 95: p. 7885.

41. Scialfa, C.T., et al., A comparison of static and dynamic hazard perception tests. Accid Anal Prev, 2013. 51: p. 268-73.

42. Rosenbloom, T., et al., Hazard perception test for pedestrians. Accident Analysis \& Prevention, 2015. 79: p. 160-169.

43. Lehtonen, E., et al., Evaluating bicyclists' risk perception using video clips: Comparison of frequent and infrequent city cyclists. Transportation Research Part F: Traffic Psychology and Behaviour, 2016. 41: p. 195-203.

44. Vansteenkiste, P., et al., A hazard-perception test for cycling children: An exploratory study. Transportation Research Part F: Traffic Psychology and Behaviour, 2016. 41: p. 182-194.

45. Cavallo, V., et al., A street-crossing simulator for studying and training pedestrians. Transportation Research Part F: Traffic Psychology and Behaviour, 2017.

46. Schwebel, D.C., et al., Community-based pedestrian safety training in virtual reality: A pragmatic trial. Accident Analysis \& Prevention, 2016. 86: p. 9-15.

47. Ducheyne, F., et al., Effects of a cycle training course on children's cycling skills and levels of cycling to school. Accident Analysis \& Prevention, 2014. 67: p. 49-60.

48. Lachapelle, U., R.B. Noland, and L.A. Von Hagen, Teaching children about bicycle safety: An evaluation of the New Jersey Bike School program. Accident Analysis \& Prevention, 2013. 52: p. 237249.

49. McLaughlin, K.A. and A. Glang, The Effectiveness of a Bicycle Safety Program for Improving SafetyRelated Knowledge and Behavior in Young Elementary Students. Journal of Pediatric Psychology, 2010. 35(4): p. 343-353.

50. Isler, R.B. and N.M. Isler, Online video simulations as an effective way of teaching drivers new road rules

in Australasian Road Safety Research Policing and Education Conference 2012. 2012: Wellington, New Zealand.

51. Isler, R.B. and N.J. Starkey, Driver Education and Training as evidence-based road safety Interventions

in Australasian Road Safety Research, Policing and Education Conference 2012. 2012: Wellington, New Zealand.

52. Petzoldt, T., et al., Can driver education be improved by computer based training of cognitive skills? Accid Anal Prev, 2013. 50: p. 1185-92.

53. Stubbé, H., et al., E-learning sudan, formal learning for out-of-school children. , . Electronic Journal of E-Learning, 2016. 14(2): p. 136-149. . 
Riaz, M.S.; Cuenen, A.; Janssens, D.; Brijs, K.; Wets, G.

54. Henderson, J. and S. Alexander, e-Learning - The future of child and adolescent obesity! Obesity Research \& Clinical Practice, 2012. 6: p. 75.

55. Çakıroğlu, Ü., et al., Gamifying an ICT course: Influences on engagement and academic performance. Computers in Human Behavior, 2017. 69: p. 98-107.

56. Hargreaves, D.J. and G.M. Davies, The development of risk-taking in children. Current Psychology, 1996. 15(1): p. 14-29.

57. Costa, C., H. Alvelos, and L. Teixeira, The Use of Moodle e-learning Platform: A Study in a Portuguese University. Procedia Technology, 2012. 5: p. 334-343.

58. Oproiu, G.C., A Study about Using E-learning Platform (Moodle) in University Teaching Process. Procedia - Social and Behavioral Sciences, 2015. 180: p. 426-432.

59. Goulão, M.d.F. and R.C. Menedez, Learner Autonomy and Self-regulation in eLearning. Procedia Social and Behavioral Sciences, 2015. 174: p. 1900-1907.

60. Sørebø, Ø., et al., The role of self-determination theory in explaining teachers' motivation to continue to use e-learning technology. Computers \& Education, 2009. 53(4): p. 1177-1187.

61. Fryer, L.K. and H.N. Bovee, Supporting students' motivation for e-learning: Teachers matter on and offline. The Internet and Higher Education, 2016. 30: p. 21-29.

62. Sailer, M., et al., Psychological Perspectives on Motivation through Gamification. Vol. 19. 2013. 1837.

63. Albert, R.R. and K.G. Dolgin, Lasting effects of short-term training on preschoolers' street-crossing behavior. Accid Anal Prev, 2010. 42(2): p. 500-8.

64. Meyer, S., F. Sagberg, and R. Torquato, Traffic hazard perception among children. Transportation Research Part F: Traffic Psychology and Behaviour, 2014. 26: p. 190-198.

65. Thomson, J.A. and K. Ampofo-Boateng, Child pedestrian accidents: a case for preventive medicine. Health Education Research, 1990. 5(2): p. 265-274.

66. Isoba, M.C., Relationship Between Theoretical Knowledge and Behavior in Traffic Planning: Implementation and Results of an Awareness Program for a Developing Country by $a$ Nongovernmental Organization. Traffic Injury Prevention, 2002. 3(4): p. 262-265.

67. Schagen, I. and K. Brookhuis, Training young cyclists to cope with dynamic traffic situations. Vol. 26. 1994. 223-30.

68. Klawe, M.M. Computer games, education and interfaces: The E-GEMS project. in The graphics interface conference. 1999.

69. Filsecker, M. and D.T. Hickey, A multilevel analysis of the effects of external rewards on elementary students' motivation, engagement and learning in an educational game. Computers \& Education, 2014. 75: p. 136-148.

70. Davis, K. and S. Singh, Digital badges in afterschool learning: Documenting the perspectives and experiences of students and educators. Computers \& Education, 2015. 88: p. 72-83.

71. Ong, C.-S. and J.-Y. Lai, Gender differences in perceptions and relationships among dominants of elearning acceptance. Computers in Human Behavior, 2006. 22(5): p. 816-829.

72. Vlachos, F. and A. Papadimitriou, Effect of age and gender on children's reading performance: The possible neural underpinnings. Cogent Psychology, 2015. 2(1): p. 1045224.

73. Harrison, A. Road safety: Insurers show accidents near schools. 2013; Available from: https://www.bbc.com/news/education-23899232.

74. Capuano, N., et al. An Ontology-Based Approach for Context-Aware E-learning. in 2011 Third International Conference on Intelligent Networking and Collaborative Systems. 2011.

75. Zeedyk, M.S., et al., Children and road safety: Increasing knowledge does not improve behaviour. British Journal of Educational Psychology, 2001. 71(4): p. 573-594.

76. Clabaux, N., et al., Motorcyclists' speed and "looked-but-failed-to-see" accidents. Accid Anal Prev, 2012. 49: p. 73-7. 
Evaluation of a gamified e-learning platform to improve traffic safety among elementary school pupils in Belgium 